www.nature.com/pj

\title{
Electron-induced reactive processing of thermoplastic vulcanizate based on polypropylene and ethylene propylene diene terpolymer rubber
}

\begin{abstract}
Varun Thakur ${ }^{1}$, Uwe Gohs ${ }^{1}$, Udo Wagenknecht ${ }^{1}$ and Gert Heinrich ${ }^{1,2}$
Thermoplastic vulcanizate (TPV) was prepared by in situ cross-linking of the rubber phase by high-energy electrons during melt mixing with a thermoplastic. The electron accelerator was directly coupled with the mixing device to cross-link the rubber phase in situ. The effect of the electron energy and absorbed dose per rotation on the properties and morphology of the TPV was studied. An absorbed dose of $100 \mathrm{kGy}$ and a dose per rotation of $90 \mathrm{kGy}$ per rotation resulted in a TPV with the best set of mechanical properties, as confirmed by morphological analysis too. The effect of different blend ratios was also studied, and it was found that a 50:50 blend ratio produced TPV with superior mechanical properties compared with 30:70 blends, as confirmed by the morphological analysis. A mechanism for the observed improvement in mechanical properties was proposed, based on the viscosity ratio of the blend components and the blend ratio. Finally, the effect of the premixing time of the blend components on the mechanical properties and morphology before the electron-induced reactive processing (EIReP) was studied. A premixing time of $14 \mathrm{~min}$ was required to achieve the optimum dispersion of the rubber phase in the thermoplastic phase before in situ cross-linking.
\end{abstract}

Polymer Journal (2012) 44, 439-448; doi:10.1038/pj.2012.3; published online 14 March 2012

Keywords: absorbed dose; blend ratio; electron energy; high-energy electrons; premixing time; thermoplastic vulcanizate

\section{INTRODUCTION}

For decades, significant attention has been given to thermoplastic elastomers and TPVs from both scientific and industrial points of view. ${ }^{1-5}$ TPVs combine the elastic and mechanical properties of crosslinked rubbers with the melt processability of thermoplastics. ${ }^{6-8}$ TPVs are prepared by a process called dynamic vulcanization in which the rubber phase is selectively cross-linked during melt mixing with a thermoplastic. The dynamic vulcanization process was first reported by Gessler ${ }^{9}$ in 1962, and then further developed by Fisher ${ }^{10}$ as well as Coran and Patel. ${ }^{11,12}$

Most commercial TPVs are based on blends of EPDM rubber as the dispersed cross-linked rubber and PP as the thermoplastic matrix. PP is one of the most widely used polymers; it has excellent stiffness and tensile properties, but owing to its high glass-transition temperature, it exhibits poor impact strength at low temperatures, which limits its applications. Thus, it is often blended with an elastomer such as EPDM to improve its impact properties. When EPDM is blended with $\mathrm{PP}$ in the melt state to produce a thermoplastic elastomer or TPV, one of the major concerns is to achieve a finer dispersion of EPDM into the PP matrix because properties such as tensile strength, elastic recovery, and impact strength can be improved by reducing the size of the EPDM particles. ${ }^{13,14}$ The tensile properties of the TPVs depend mainly on the blend composition, the cross-link density of the rubber phase, the state of the rubber dispersion, and the rubber domain size. EPDM/PP-based TPVs are traditionally cross-linked with acidactivated resol, ${ }^{15,16}$ but because of the consequent off-white color and the formation of black specks, other cross-linking systems have been developed, such as platinum-catalyzed hydrosilane and peroxide/ coagent. ${ }^{17,18}$ Despite having several advantages, there are certain disadvantages of the peroxide system. The decomposition products formed during the cross-linking are extremely volatile and give the product a foul smell. Peroxide-cross-linked TPVs also demonstrate a blooming effect, in which some of the degraded products formed during the cross-linking bloom to the surface of the TPV and result in discoloration of the product. The peroxide system requires a coagent to enhance the cross-linking efficiency of the peroxide. Further, the peroxide has to be homogeneously dispersed and heated to generate radicals in the polymer.

Thus, an alternative process for the preparation of TPVs is required to enable the cross-linking of elastomer in TPVs. Electron-induced reactive processing (EIReP) of EPDM/PP blends presents such a novel approach; in this approach, the EPDM phase is cross-linked and grafted to PP by high-energy electrons (without a coagent) during melt mixing with PP. In this novel approach, an electron accelerator is 
directly coupled with the mixing device, and the cross-linking of EPDM is performed during melt mixing with PP without a coagent. In Naskar et al., ${ }^{19}$ we described the effect of the absorbed dose and the electron treatment time on the properties and morphology of PP-EPDM TPVs, and demonstrated that an absorbed dose of $100 \mathrm{kGy}$ and an electron treatment time of $15 \mathrm{~s}$ provide the best set of mechanical properties, together with the finer dispersion of EPDM particles in PP. In the present work, the effects of the absorbed dose and the absorbed dose per rotation on the properties and morphology of PP-EPDM TPVs are discussed in detail. The effect of different blend ratios is also discussed, and based on rheological studies, a mechanism is proposed to explain the influence of the viscosity ratio and blend ratio of blend components on the morphology and properties of the TPVs. The effect of premixing time on the morphology and final properties of the TPVs is also discussed.

\section{EXPERIMENTAL PROCEDURE}

\section{Materials}

The commercial isotactic PP (PP HD 120 MO; melt flow index: 8 g per 10 min at $230^{\circ} \mathrm{C}$ and $2.16 \mathrm{~kg}$; density: $0.91 \mathrm{~g} \mathrm{~cm}^{-3}$ ) was supplied by Borealis (Schwechat,

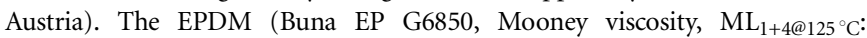
60; diene content: $7.7 \%$; density: $0.86 \mathrm{~g} \mathrm{~cm}^{-3}$ ) was supplied by Lanxess (Leverkusen, Germany). Figure 1 shows the chemical structures of PP and EPDM.

\section{EIReP of PP-EPDM TPVs}

Figure 2 shows the schematic setup, whereby an electron accelerator is directly coupled to the mixing chamber. The EIReP of PP-EPDM TPVs was performed by melt mixing of PP and EPDM in a Brabender plasticorder (Brabender, Duisburg, Germany) for a total mixing time of $15 \mathrm{~min}$ and a rotor speed of 45 r.p.m. The average mixing temperature was $180^{\circ} \mathrm{C}$. The process parameters, that is, the absorbed dose and the dose per rotation, were varied to obtain the best set of parameters. The blend ratio was varied to observe the effect of the blend ratio on the properties and morphology of TPVs. The premixing time before EIReP was also varied.

\section{Characterization}

The tensile properties of all the samples were investigated using a universal tensile testing machine (Zwick Roell, Ulm, Germany). TPVs were tested at a crosshead speed of $50 \mathrm{~mm} \mathrm{~min}^{-1}$. The tensile strength, modulus at $300 \%$ elongation, and elongation at break were measured. The elastic modulus (Emodulus) was calculated at the very beginning of the strain application within $0.05-0.25 \%$ strain. The test specimens were prepared by injection molding, and at least five specimens were tested for each sample to obtain statistically significant results. The Izod impact strength measurements were also performed on notched and unnotched specimens at $23^{\circ} \mathrm{C}$ and $50 \%$ relative humidity. For the dynamic mechanical measurements, the temperature sweeps for the TPVs specimens were performed under tension mode by an Eplexor 150N (GABO, Ahlden, Germany) apparatus from -80 to $+140^{\circ} \mathrm{C}$ at a frequency of $10 \mathrm{~Hz}$. The static and dynamic loads on the sample were $0.5 \%$ and $\pm 0.2 \%$, respectively. The heating rate selected was $4 \mathrm{~K} \mathrm{~min}^{-1}$. The morphology of the PP-EPDM TPVs was investigated using scanning electron microscope (SEM Ultra Plus, Carl Zeiss SMT, Jena, Germany) imaging. To prepare the samples for SEM imaging, the samples were placed over a sticky surface made by conductive carbon cement on a SEM sample holder and then coated with platinum (layer thickness $15 \mathrm{~nm}$ ), using a sputter coater (BAL-TEC SCD 500 Sputter Coater, Leica, Wetzlar,<smiles>C[Te]CC(C)C</smiles>

PP

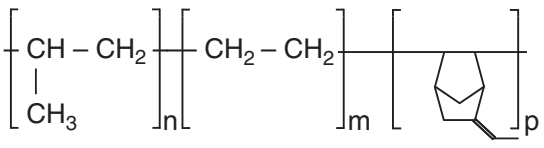

EPDM
Figure 1 The chemical structures of PP and EPDM.
Germany). The apparent shear stress and shear viscosities were determined using a high-pressure capillary rheometer (Rheograph 2002, Göttfert, Buchen, Germany) with a capillary die of $1 \mathrm{~mm}$ diameter and L/D ratio (the ratio of the length of the screw to its diameter) of 20. All the measurements were performed at $200{ }^{\circ} \mathrm{C}$, over a shear rate range between 5 and $4000 \mathrm{~s}^{-1}$. The sample was placed in the barrel and forced through the capillary with a piston attached to the moving crosshead. Differential scanning calorimeter measurements were performed using a DSC Q1000 (TA instruments, New Castle, DE, USA). The scans were taken in the temperature range from -80 to $200{ }^{\circ} \mathrm{C}$ with a programmed heating rate of $10 \mathrm{~K} \mathrm{~min}^{-1}$ under an $\mathrm{N}_{2}$ atmosphere.

\section{RESULTS AND DISCUSSION}

Effect of the absorbed dose and the electron dose per rotation

The absorbed dose and the dose per rotation are two important parameters that can influence the properties and morphology of TPVs during EIReP. Three different doses (50, 75, and $100 \mathrm{kGy})$ and three different dose per rotation values (70,90, and $110 \mathrm{kGy}$ per rotation) were selected to observe their influence on the formation of TPVs. Figure 3 shows the variation of tensile strength of the TPVs treated at different absorbed dose and at different dose per rotation values. Both the absorbed dose and the dose per rotation have a profound effect on the tensile strength of the TPVs formed. TPVs treated at 70 and $110 \mathrm{kGy}$ per rotation showed a significant increase in the tensile strength when the dose was increased from 50 to $75 \mathrm{kGy}$. However, for the $100 \mathrm{kGy}$ dose, the tensile strength did not exhibit a significant increase. However, TPVs treated at $90 \mathrm{kGy}$ per rotation showed a marginal increase in the tensile strength when the dose was increased from 50 to $75 \mathrm{kGy}$. Interestingly, when the dose was increased to $100 \mathrm{kGy}$, the tensile strength of the TPV increased abruptly to $14 \mathrm{MPa}$, which was the highest for all TPVs prepared.

Figure 4 shows the variation of elongation at break of TPVs treated at different absorbed doses and at different dose per rotation values. The variation of elongation at break was quite similar to that of the

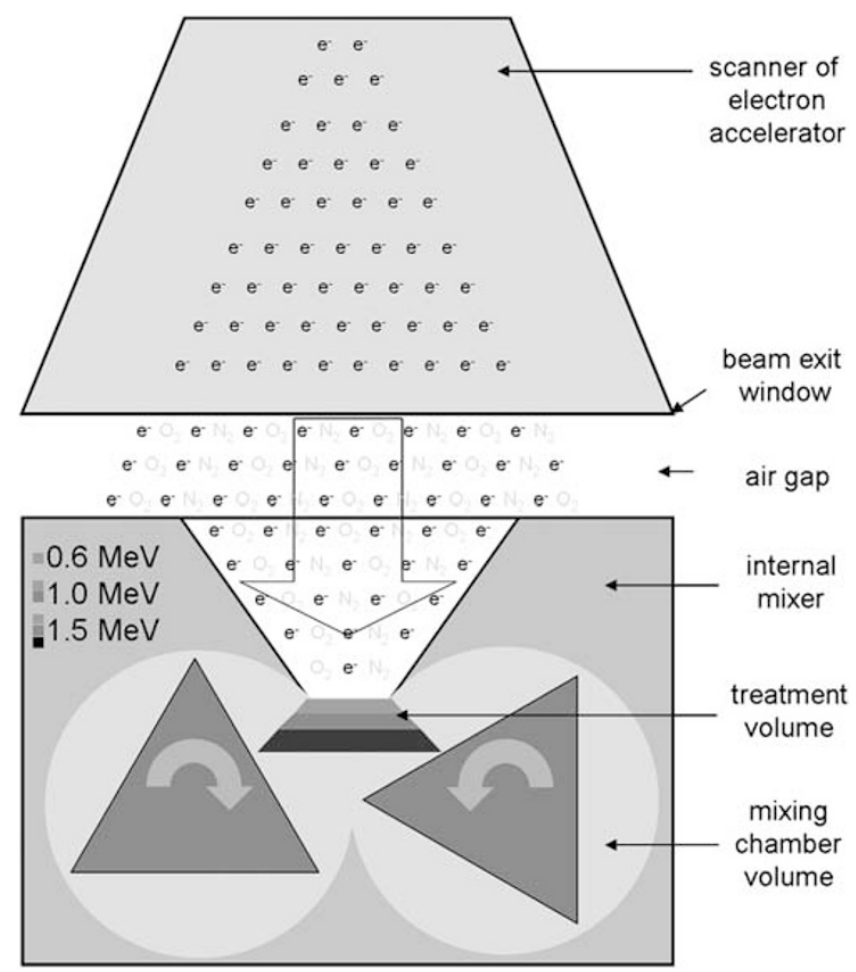

Figure 2 Schematic of the experimental set up in which the electron accelerator is directly coupled to the mixing chamber. 


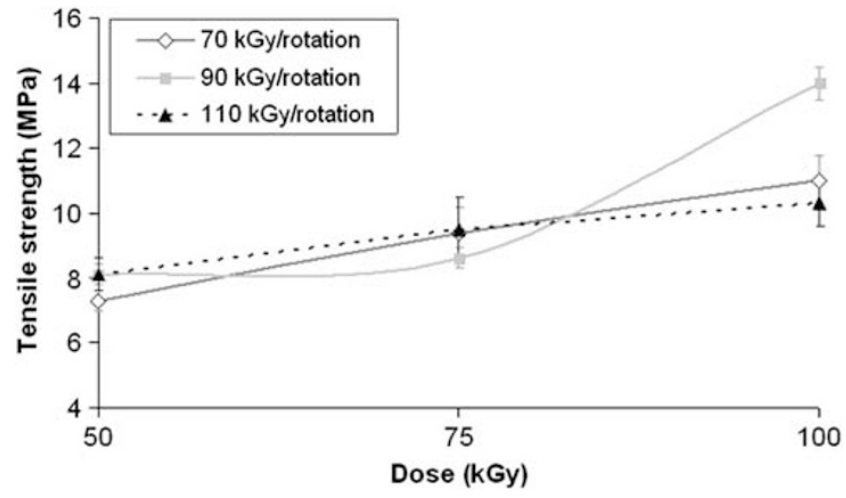

Figure 3 Variation of the tensile strength of the TPVs treated with different absorbed dose and dose per rotation.

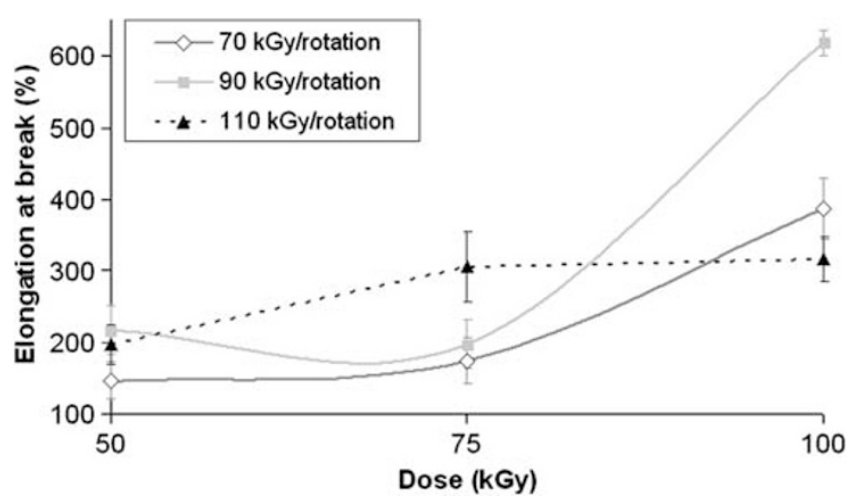

Figure 4 Variation of the elongation at break of the TPVs treated with different absorbed dose and dose per rotation.

tensile strength at different doses and dose per rotation values. The elongation at break values increased as the dose increased from 50 to $100 \mathrm{kGy}$ for $70 \mathrm{kGy}$ per rotation. For $90 \mathrm{kGy}$ per rotation, the elongation at break first showed no significant change at $75 \mathrm{kGy}$ and then increased abruptly at $100 \mathrm{kGy}$. For $110 \mathrm{kGy}$ per rotation, the elongation at break was first increased and then showed a decrease at higher dose values. The maximum elongation at break value $(618 \%)$ was observed for the TPVs treated with $100 \mathrm{kGy}$ absorbed dose at $90 \mathrm{kGy}$ per rotation. Thus, the TPVs treated at $100 \mathrm{kGy}$ and $90 \mathrm{kGy}$ per rotation exhibited the best set of mechanical properties. It seems that $100 \mathrm{kGy}$ is the optimum absorbed dose for the production of PP-EPDM TPVs. This optimal absorbed dose correlates with the hardness values of pure EPDM rubber (Figure 5) treated at different doses at room temperature. The hardness of pure EPDM rubber reached a maximum at $100 \mathrm{kGy}$, followed by a plateau and then by a decrease in the hardness values, which indicated degradation at higher doses. The dose of $100 \mathrm{kGy}$ was also sufficient for PP, as higher doses will lead to the degradation of PP.

Figure 6 shows the SEM images of the TPVs prepared ( $x / y$ : where $x$ is dose and $y$ is dose per rotation). The effect of the dose and dose per rotation value was clearly observed from the SEM images. At $50 \mathrm{kGy}$, the SEM images showed a similar type of morphology for all the TPVs prepared at different dose per rotation values. The morphology of the TPVs prepared at $50 \mathrm{kGy}$ showed a mixture of co-continuous and dispersed morphology. This morphology is attributed to insufficient cross-linking of the EPDM phase at $50 \mathrm{kGy}$, which produces undercured EPDM rubber agglomerates that are not able to break down into

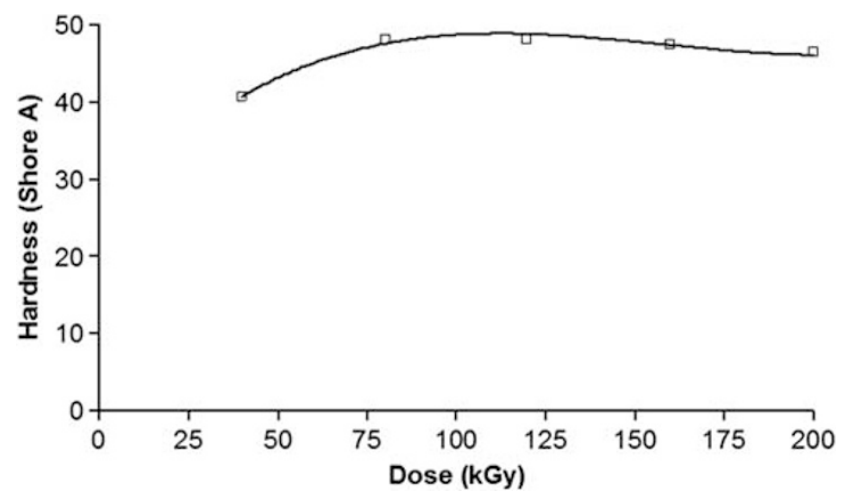

Figure 5 Variation of the hardness of pure EPDM rubber with increasing absorbed dose at room temperature.

smaller cross-linked particles. This morphology was also reflected in the lower tensile strength and lower elongation at break values (Figures 3 and 4) in TPVs prepared at $50 \mathrm{kGy}$ compared with the other TPVs that were prepared. The morphology changed when the absorbed dose increased from $50 \mathrm{kGy}$ to $75 \mathrm{kGy}$. The dispersed EPDM particles were clearly visible in the SEM images of the TPVs treated with $75 \mathrm{kGy}$ at different dose per rotation values. The EPDM particles were dispersed uniformly throughout the continuous PP phase in the 75/110 sample compared with the 75/70 and 75/90 samples. This uniform dispersion was also indicated from the enhanced tensile strength $(10 \mathrm{MPa})$ and elongation at break (390\%) values for the 75/110 sample compared with the $75 / 70$ and $75 / 90$ samples. At $100 \mathrm{kGy}$, all of the TPVs prepared at different dose per rotation values exhibited a good set of mechanical properties. The TPV prepared with $100 \mathrm{kGy}$ and $90 \mathrm{kGy}$ per rotation showed the maximal tensile strength $(14 \mathrm{MPa})$ and elongation at break (618\%) values compared with the 100/70 and 100/110 samples. From the SEM images, a broad distribution of EPDM particle sizes was evident in the TPVs prepared. There were rubber particle sizes ranging from $>1 \mu \mathrm{m}$ to a few hundreds of nanometers. The latter type of morphology was more prominent in the 100/90 sample, which showed superior mechanical properties when compared with all other TPVs.

Thus, it was concluded from the mechanical and SEM studies that the absorbed dose and dose per rotation have a significant influence on the properties and morphology of the TPVs prepared. The TPV prepared with $100 \mathrm{kGy}$ and $90 \mathrm{kGy}$ per rotation exhibited an inhomogeneous distribution of EPDM particle sizes throughout the continuous PP phase.

Figure 7 shows the variation of the storage modulus with temperature in the dynamic mechanical analysis of the TPVs prepared. The dynamic mechanical studies (Figure 8) showed no significant change in the storage modulus, as well as in the tan delta, for the different TPVs prepared. There was no significant shift in the tan delta peak, whereas the peak height was reduced in most of the TPVs formed. This is attributed to enhanced cross-linking with a higher absorbed dose. Thus, there was no change in the dynamic mechanical properties of the TPVs, and the superior mechanical properties previously found for TPVs are attributed to the different morphology obtained exclusively during the EIReP.

\section{Effect of premixing time before EIReP}

It was observed that the TPVs with inhomogeneous morphology of the dispersed EPDM particles in PP exhibited the best set of mechanical properties. Goharpey et al. ${ }^{20}$ proposed a four-step mechanism for morphology development in TPVs during dynamic vulcanization 

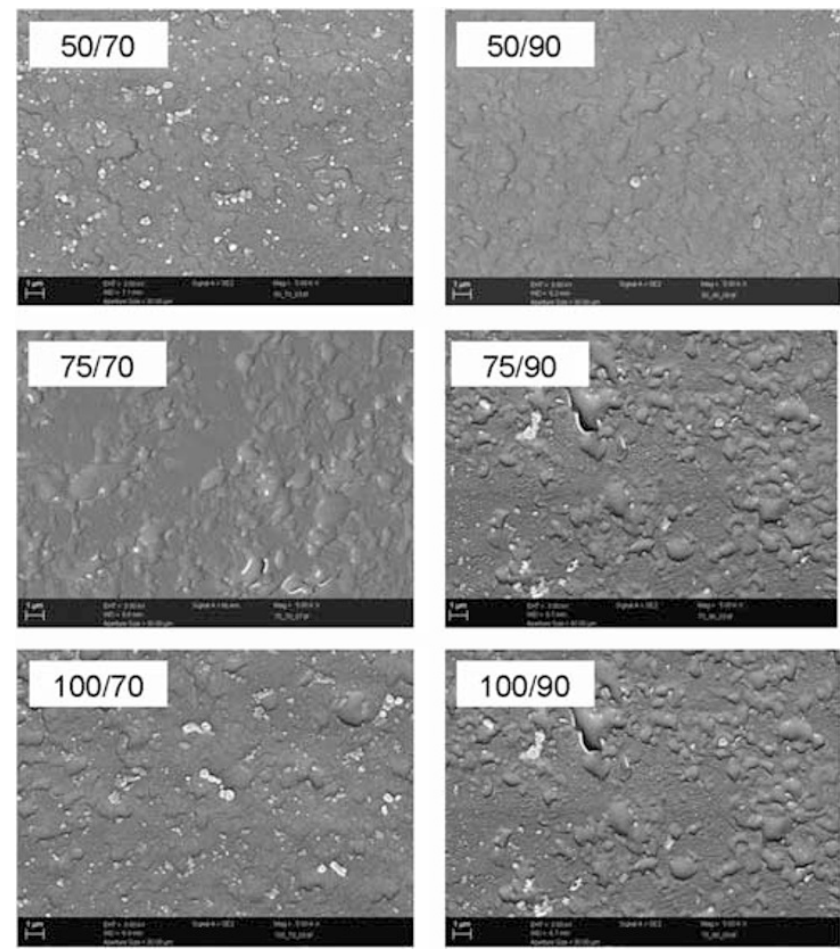
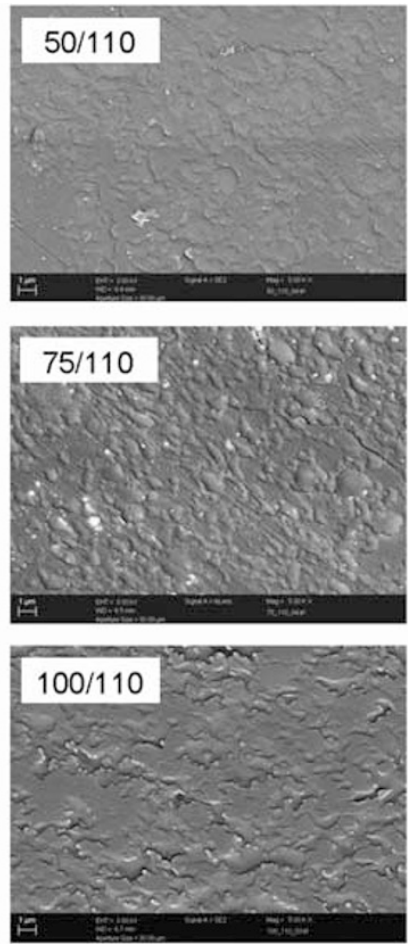

Figure 6 SEM images of all of the TPVs prepared ( $x / y$ : where $x$ is dose and $y$ is dose per rotation; scale: $1 \mu \mathrm{m}, 5 \mathrm{kX}$ ).

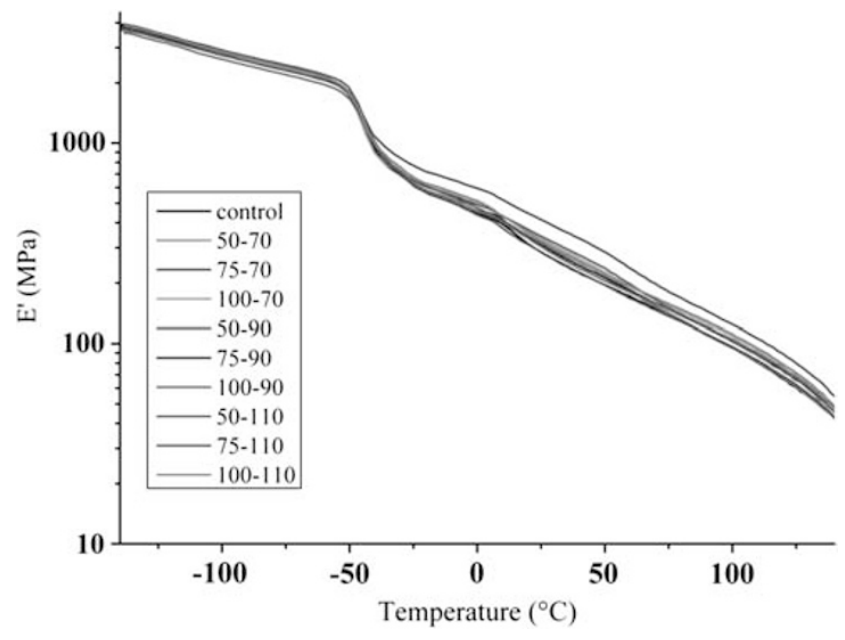

Figure 7 Storage modulus $\left(E^{\prime}\right)$ versus temperature for all of the TPVs in the dynamic mechanical studies.

(Figure 9). The first step involves the melt dispersion of the EPDM phase in PP, which is associated with rubber-phase droplet breakup and coalescence before the onset of vulcanization. During dynamic vulcanization, agglomeration of cross-linked rubber particles takes place together with the droplet breakup process. As vulcanization proceeds, the interfacial adhesion between the two phases increases. The breakdown of the agglomerates takes place as a result of the increase in the interfacial adhesion and applied shear forces, which ultimately results in the dispersion of rubber particles into the continuous phase. There is vast literature available on different aspects of dynamic vulcanization (steps 2, 3, and 4 in Figure 9). However,

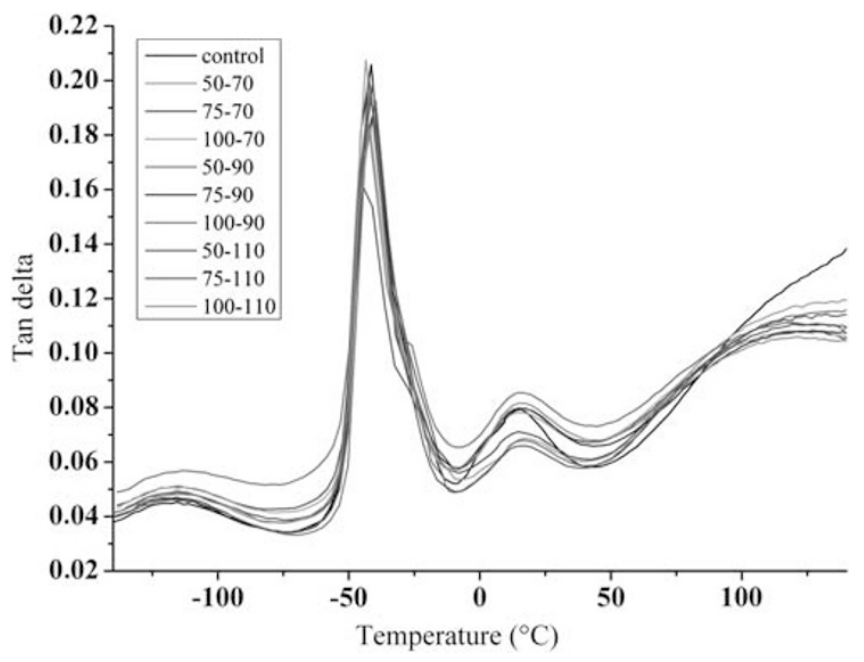

Figure 8 Tan delta versus temperature for all of the TPVs in dynamic mechanical studies.

there is hardly any study available in which the influence of the mixing time before dynamic vulcanization is studied (step 1 in Figure 9). Thus, the influence of the mixing time before EIReP on the final properties of TPVs is described in this section. The equilibrium between the rubber-phase breakup and coalescence during melt mixing with a thermoplastic is an important step in the preparation of TPVs, and determines the final properties of the TPVs.

To study the effect of premixing time, the mixing time before EIReP was varied $(8,11$, and $14 \mathrm{~min})$ whereas the total mixing time was kept constant at $16 \mathrm{~min}$. An absorbed dose of $100 \mathrm{kGy}$ and a dose per rotation of $90 \mathrm{kGy}$ per rotation were chosen because these conditions 
1. Melt Mixing
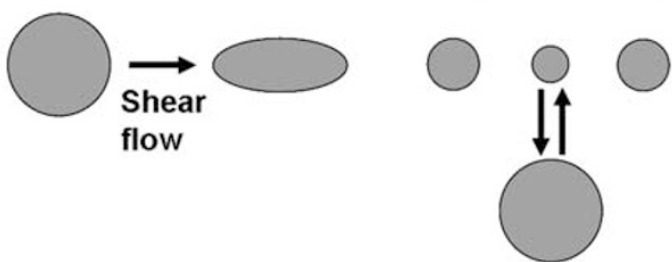

Coalescense

\section{Dynamic vulcanization}

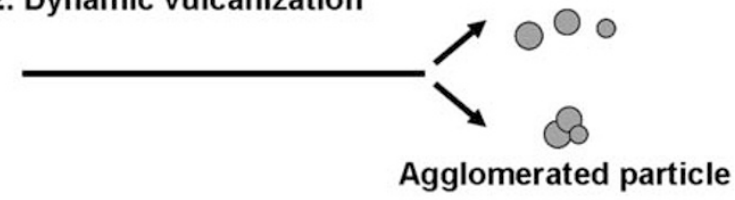

\section{Increase in surface tension of the crosslinked rubber particles leading to the break down of the agglomerates}

\section{Dispersion of rubber particles}

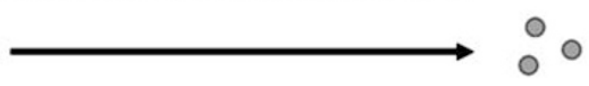

Figure 9 Schematic diagram of morphology development during dynamic vulcanization.

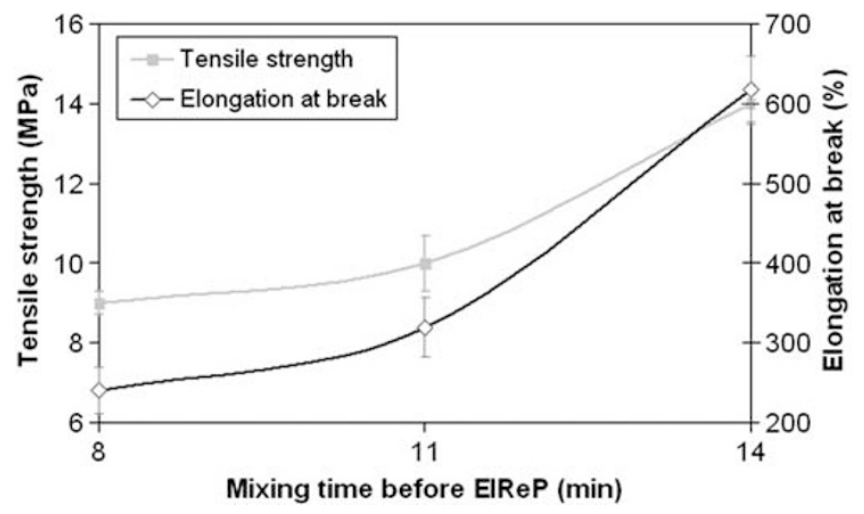

Figure 10 Variation of the tensile strength and elongation at break with different mixing times before EIReP.

provided the best set of mechanical properties for TPVs. The mixing time before EIReP for this TPV was $14 \mathrm{~min}$. Figure 10 shows the variation of tensile strength and elongation at break for the TPVs prepared with mixing times before EIReP of 8,11 , and 14 min. The pronounced effect of the mixing time before EIReP was clearly observed from the mechanical properties of the corresponding TPVs. For the premixing time of $8 \mathrm{~min}$, the tensile strength and elongation at break values for the TPV were $9 \mathrm{MPa}$ and $240 \%$, respectively. The tensile strength and elongation at break values increased to $10 \mathrm{MPa}$ and $320 \%$ when the premixing time was increased to $11 \mathrm{~min}$. The tensile strength and elongation at break values reached a maximum of $14 \mathrm{MPa}$ and $618 \%$, respectively, for the premixing time of $14 \mathrm{~min}$. This trend shows the importance of the premixing stage in TPV formation before EIReP. When EPDM is mixed with PP, it initially forms a co-continuous phase in which neither EPDM nor PP is the continuous phase. As mixing continues, an equilibrium is established between the rubber-phase breakup and coalescence, which determines the final phase morphology just before EIReP. During EIReP, the cross-linked rubber particles break down into smaller dispersed particles because of applied shear forces and increasing interfacial adhesion between the two phases during melt mixing. The final size of these dispersed rubber particles also depends on the morphology and distribution of the rubber phase before EIReP. This dependence was clearly reflected in the mechanical properties of TPVs, which increased as the premixing time increased from $8 \mathrm{~min}$ to $14 \mathrm{~min}$.

Figure 11 shows the SEM images of the corresponding thermoplastic polyolefins (TPOs) and TPVs prepared with premixing times of 8,11 , and $14 \mathrm{~min}$. In the case of the TPOs, the mixing was stopped just before EIReP to observe the state of dispersion of the EPDM phase in PP after premixing times of 8,11 , and $14 \mathrm{~min}$. As the premixing time before EIReP increased from $8 \mathrm{~min}$ to $14 \mathrm{~min}$, the EPDM phase became more and more dispersed into the continuous PP phase. At a premixing time of $8 \mathrm{~min}$, EPDM was not well dispersed into the PP phase and formed a co-continuous phase with the latter. After EIReP, phase inversion took place and thus, EPDM formed a dispersed phase with larger particle sizes. Hence, the resulting tensile strength (9MPa) and the elongation at break (240\%) values were inferior to that of other TPVs. When the premixing time was increased to $11 \mathrm{~min}$, EPDM was better dispersed into the PP compared with the 8 min premixing time case and formed a dispersed-phase morphology in PP. During EIReP, phase inversion takes place, and EPDM was dispersed in PP with a smaller particle size compared with TPV with a shorter premixing time. This smaller EPDM particle size was also reflected in the improved tensile strength $(10 \mathrm{MPa})$ and elongation at break (320\%) values for the TPV for which the premixing time was $11 \mathrm{~min}$.

When the premixing time was increased to $14 \mathrm{~min}$, EPDM was homogeneously dispersed in the continuous PP phase, and the phase inversion occurred before EIReP. Thus, EIReP resulted in the breakdown of the dispersed EPDM phase into smaller particles with a broad distribution of particle size. Hence, TPVs prepared with a premixing time of 14 min resulted in a broad particle size distribution of EPDM in the PP phase, and this may be responsible for the superior tensile strength $(14 \mathrm{MPa})$ and elongation at break $(618 \%)$ values of the resulting TPV.

These results demonstrate that the premixing time of PP and EPDM before EIReP has a significant influence on the morphology, and hence the mechanical properties, of the resulting TPVs.

\section{Effect of different blend ratios}

The effect of different PP-EPDM blend ratios was studied. Two different blend ratios (30/70 and 50/50 PP/EPDM) were selected to study the influence of blend ratio on the mechanical, morphological, thermal, impact, and rheological properties of the TPVs. The TPVs were prepared with $100 \mathrm{kGy}$ absorbed dose, $90 \mathrm{kGy}$ per rotation, and 14 min premixing time, which resulted in the best set of properties.

Figure 12 shows the variation of tensile strength and elongation at break for the TPVs prepared with two blend ratios via EIReP. The control samples are also shown.

The effect of the blend ratio is clearly visible in Figure 12. TPVs prepared with a 30/70 blend ratio showed a marginal increase in the tensile strength $(5.6 \mathrm{MPa})$, whereas the elongation at break (233\%) showed a small decrease compared with the corresponding control sample (4.9 MPa; 262\%). However, the tensile strength (14 MPa) and elongation at break (618\%) of the TPVs prepared with a 50/50 blend ratio were almost double those of the control sample (8.5 MPa; 261\%). Thus, a 50/50 blend ratio of PP/EPDM provided the best set of mechanical properties with EIReP. 

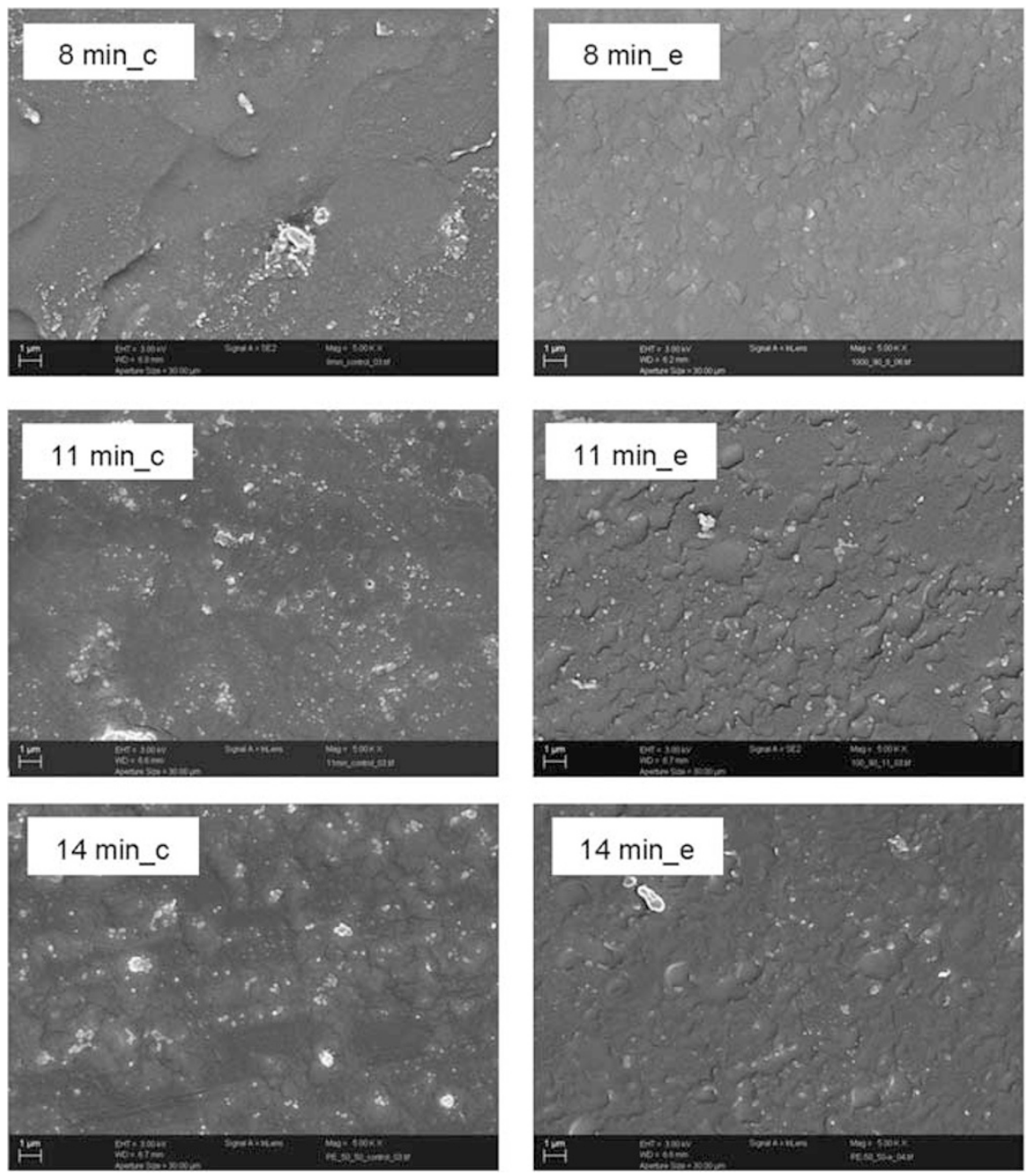

Figure 11 SEM images of the corresponding TPOs (left; scale: $2 \mu \mathrm{m}$ ) and TPVs (right; scale: $1 \mu \mathrm{m}$ ) prepared with premixing times of 8,11 , and 14 min.

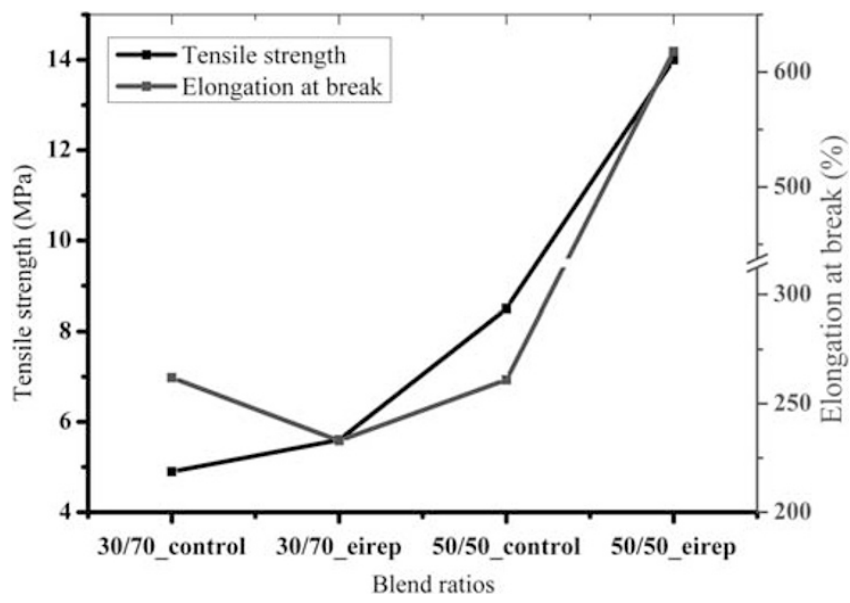

Figure 12 Variation of the tensile strength and the elongation at break for TPVs with different blend ratios.

Figure 13 shows the SEM images of the TPVs with different blend ratios along with their corresponding control samples. The morphology of the EPDM in PP was quite different in the two samples before EIReP. At a 30/70 blend ratio, the EPDM formed a co-continuous phase with PP before EIReP. After EIReP, the morphology was still co-continuous, as no phase was significantly continuous. At a 50/50 blend ratio, the EPDM was already in the dispersed phase before EIReP, and after EIReP, the EPDM was still in the dispersed phase, but with a smaller particle size. This variation in the morphologies of the two different TPVs was responsible for the different mechanical properties. The morphology of the immiscible elastomer/thermoplastic blends after the dynamic vulcanization process mainly depends on the viscosity and the composition ratio ${ }^{21-23}$ of the two blend components (Figure 14).

Figure 15 shows the variation of the apparent shear viscosity with the apparent shear rate for virgin PP and EPDM, as well as for the melts mixed for 14 and $10 \mathrm{~min}$, respectively.

The EPDM/PP viscosity ratio for virgin $\mathrm{PP}$ and $\mathrm{EPDM}$ was $\sim 10$, whereas the viscosity ratio increased to $\sim 100$ for the PP and EPDM melt mixed for 14 and $10 \mathrm{~min}$, respectively (Figure 15). The selection of 14 and 10 min were based on the premixing time for PP and EPDM before EIReP. EPDM was added to the melt mixing process $4 \mathrm{~min}$ after the addition of PP.

At a 30/70 blend ratio, because the elastomer concentration was high and the viscosity ratio just before EIReP was $\sim 100$, point $\mathrm{D}$ in Figure 14 shifts to a region of co-continuous phase, and after EIReP, point $\mathrm{E}$ remains in the co-continuous phase because of incomplete 

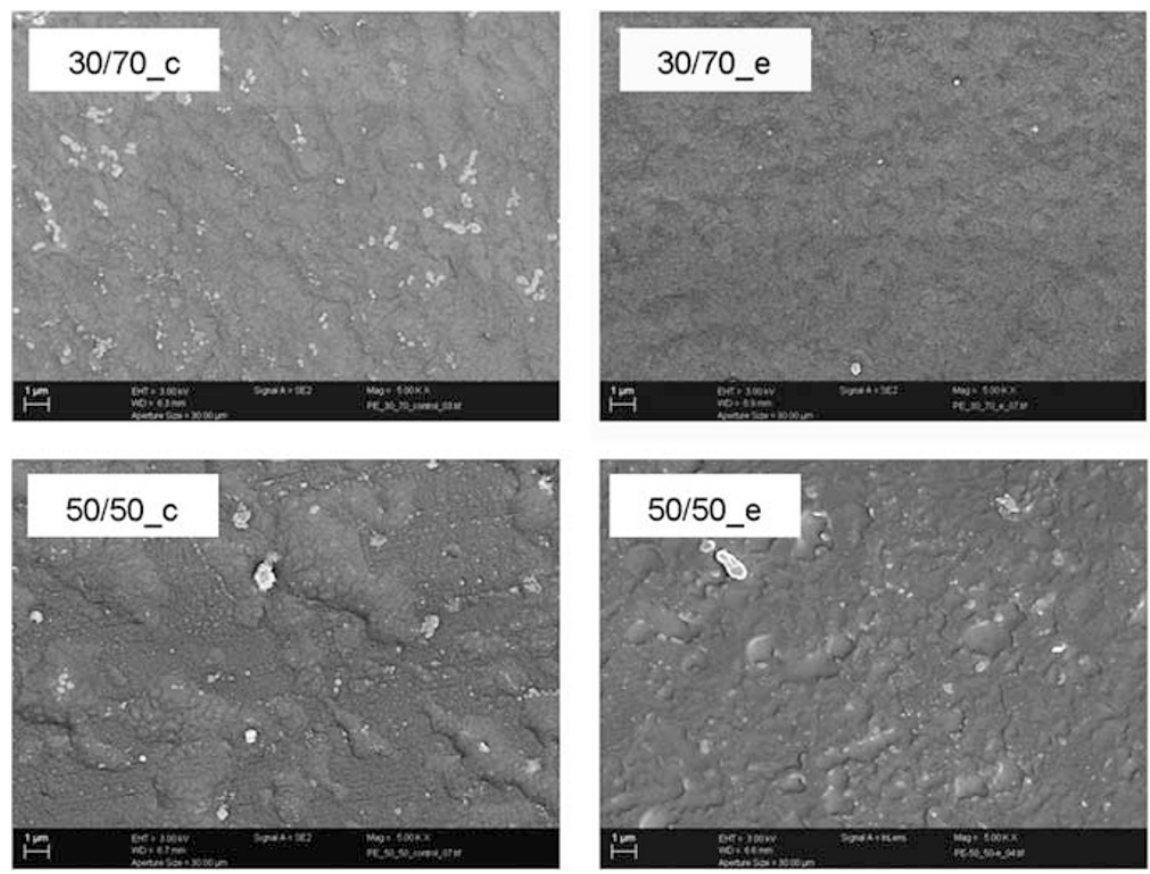

Figure 13 SEM images of the TPVs (right; scale: $1 \mu \mathrm{m}$ ) with different blend ratios along with their control samples (left; scale: $2 \mu \mathrm{m}$ ).

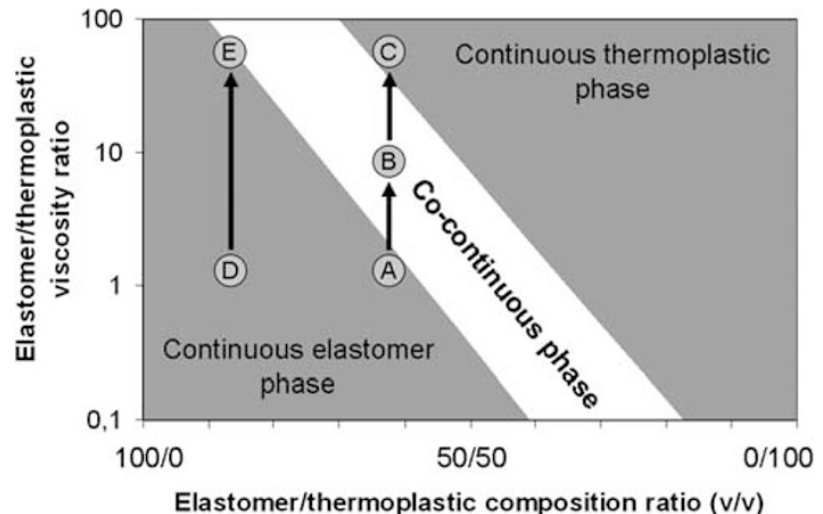

\section{$A=$ prior to crosslinking: continuous elastomer phase \\ $\mathrm{B}=$ during crosslinking; phase inversion \\ $\mathrm{C}=$ after crosslinking, continuous thermoplastic phase \\ $\mathrm{D}=$ too high elastomer concentration \\ $\mathrm{E}=$ incomplete phase inversion; co-continuous}

Figure 14 The dependence of the morphology of the elastomer/ thermoplastic blend on the composition and the viscosity ratio during melt blending.

phase inversion. The co-continuous phase was also observed from SEM pictures of the 30/70 blend in Figure 13.

At a 50/50 blend ratio, points $A$ and $B$ shift to the region of continuous thermoplastic phase before EIReP and after EIReP, and point $\mathrm{C}$ lies in the continuous thermoplastic phase (Figure 14). This behavior was also observed in the SEM images of a 50/50 blend in Figure 13, where EPDM was already dispersed in the continuous PP phase before EIReP, and after EIReP, EPDM was still in the dispersedphase morphology, but with smaller particle sizes.

The differences in the tensile strength and elongation at break of the two TPVs with different blend ratios are attributed to the different deformation mechanisms operating in the TPVs. It is known that if the rubber particle size is $>1 \mu \mathrm{m}$ the enhancement in the mechanical properties is mainly due to crazing in the rubber particles during deformation. ${ }^{24}$ However, if the rubber particle size is $<1 \mu \mathrm{m}$, the enhancement of the mechanical properties is primarily from shear deformation. In the $30 / 70 \mathrm{TPV}$, the deformation mechanism is mainly based on the crazing of the rubber particles because the rubber particle size is $>1 \mu \mathrm{m}$. In the 50/50 TPV, the deformation mechanism of TPV is dominated by shear yielding of the PP matrix. Roy l'Abee et al. ${ }^{25}$ stated that the deformation behavior of TPV is dominated by localized yielding of the PP matrix in the thin ligaments at the equatorial regions of the rubber particles. In Figure 13, the 50/50 TPV showed a broad distribution of rubber particle sizes ranging from $>1 \mu \mathrm{m}$ to a few hundreds of nanometers. It is known that rubber particles with $<1 \mu \mathrm{m}$ size cannot initiate crazes, and thus, shear yielding is the main deformation mechanism in such rubber particles. However, rubber particles with $>1 \mu \mathrm{m}$ size are able to internally cavitate, and thus, results in the local release of the applied stress during tensile deformation. Hence, in the 50/50 TPV via EIReP, crazing along with shear yielding was responsible for the superior tensile strength and elongation at break of the TPV, which is attributed to the morphology obtained after EIReP.

Table 1 shows the variation of the notched Izod impact strength for the various TPVs and their corresponding control samples. The addition of EPDM in PP resulted in superior impact strength of the corresponding control and TPV samples compared with pure PP $\left(4 \mathrm{~kJ} \mathrm{~m}^{-2}\right)$. In the case of $30 / 70$ samples, there was no break in the unnotched/notched samples even when the impact force of the striking pendulum was increased to a maximum of $25 \mathrm{~J}$. This behavior is attributed to the presence of a higher amount of EPDM, which is known to possess excellent damping properties. For the 50/50 blend ratio, there was no break in the unnotched sample, whereas the notched sample showed only a partial break (only visible under a microscope). This result showed the excellent improvement in the impact strength of the TPVs prepared. The impact strength was 

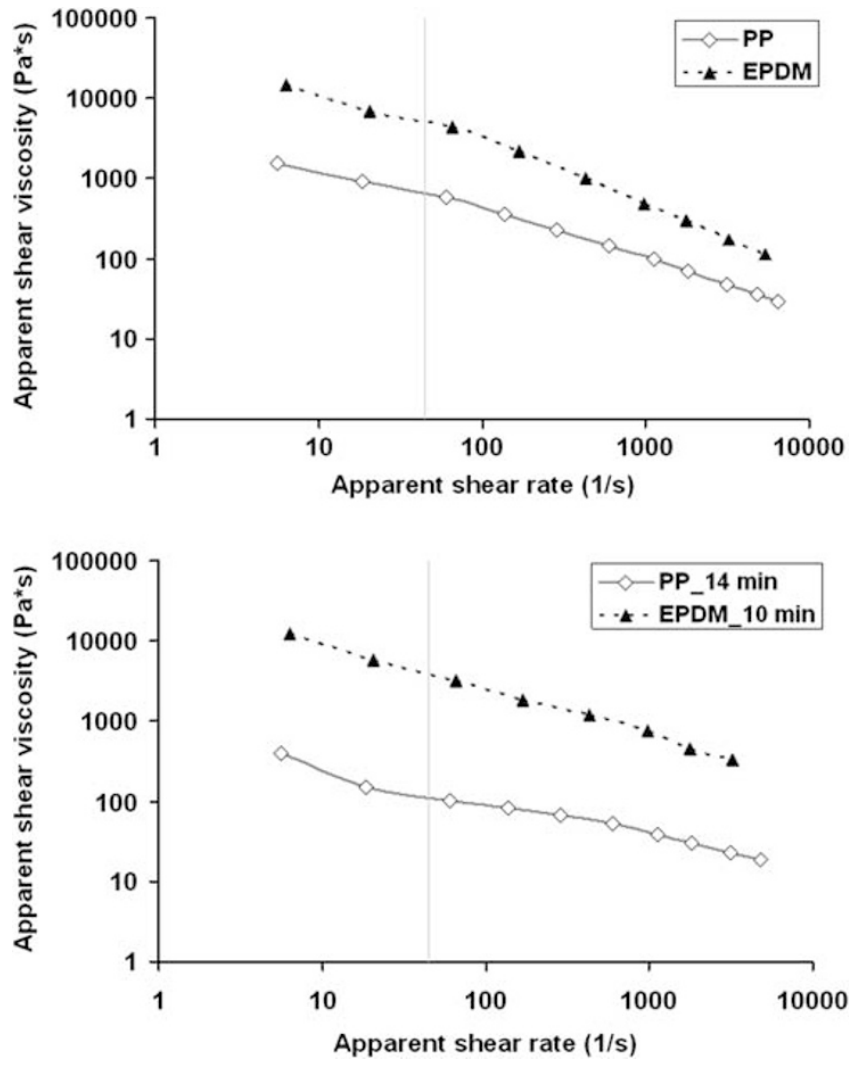

Figure 15 The variation of the apparent shear viscosity with the apparent shear rate for virgin PP and EPDM (left) as well as melt mixed for 14 and 10 min (right), respectively.

Table 1 Izod impact strength for pure PP (HD $120 \mathrm{MO}$ ), control, and TPV samples (ISO 180/1A; $23^{\circ} \mathrm{C}$ and $50 \%$ relative humidity)

\begin{tabular}{lc}
\hline Samples & Notched lzod impact strength $\left(\mathrm{kJ} \mathrm{m}^{-2}\right)$ \\
\hline Pure PP & $4^{*}$ \\
30/70_control & No break \\
30/70_electron & No break \\
50/50_control & $45.0 \pm 0.4$ (partial break $\left.{ }^{\#}\right)$ \\
50/50_electron & $54.0 \pm 1.3$ (partial break\#
\end{tabular}

Abbreviations: PP, polypropylene; TPV, thermoplastic vulcanizate.

*Value as reported from supplier's data sheet.

\#The partial break was only visible under a microscope.

significantly enhanced for 50/50 TPV $\left(54 \mathrm{~kJ} \mathrm{~m}^{-2}\right)$ compared with the corresponding control sample $\left(45 \mathrm{~kJ} \mathrm{~m}^{-2}\right)$. This higher impact strength was also evident from the excellent stress-strain properties of the 50/50 TPV sample, where the area under the stress-strain curve is an indirect indication of the toughness.

Table 2 shows the experimental data of the glass transition temperatures $\left(T_{\mathrm{g}}\right)$ of $\mathrm{PP}$ and $\mathrm{EPDM}$, as well as the melting temperature $\left(T_{\mathrm{m}}\right)$, the maximum crystallization temperature $\left(T_{\mathrm{c}, \mathrm{m}}\right)$, and the melt enthalpy $\left(\Delta \mathrm{H}_{\mathrm{m}}\right)$ for all the samples.

There was a little deviation in the $T_{\mathrm{g}}$ of PP and EPDM in the control and the TPV samples. The melting temperature $\left(T_{\mathrm{m}}\right)$ of the PP phase decreased by $2-4 \mathrm{~K}$ in both of the TPVs compared with their corresponding control samples. This decreased melting temperature is attributed to the generation of defects in the PP crystallites because of degradation of PP by high-energy electrons, ${ }^{26}$ and thus, PP melted
Table 2 Experimental data of glass transition temperatures $\left(T_{\mathrm{g}}\right)$ of PP and EPDM, melting temperature $\left(T_{\mathrm{m}}\right)$, maximum crystallization temperature $\left(T_{c, m}\right)$, and melt enthalpy $\left(\Delta \mathrm{H}_{m}\right)$ for all the samples

\begin{tabular}{lccccc}
\hline & $T_{g}\left({ }^{\circ} \mathrm{C}\right)$ & $T_{g}\left({ }^{\circ} \mathrm{C}\right)$ & $T_{m}\left({ }^{\circ} \mathrm{C}\right)$ & $T_{c, m}\left({ }^{\circ} \mathrm{C}\right)$ & $\Delta H_{m}(\mathrm{~J} / \mathrm{g})$ \\
\cline { 2 - 6 } Samples & $E P D M$ & $P P$ & 2nd heating & 1st cooling & 2nd heating \\
\hline 30/70c & -52 & -6 & 163 & 118 & $29.0 \pm 0.5$ \\
30/70e & -52 & -6 & 161 & 122 & $28.0 \pm 0.5$ \\
50/50c & -53 & -7 & 164 & 118 & $47.0 \pm 0.5$ \\
50/50e & -53 & -7 & 160 & 123 & $50.0 \pm 0.5$ \\
\hline
\end{tabular}

Abbreviations: PP, polypropylene; EPDM, ethylene propylene diene monomer.

at a lower temperature in the TPVs. The maximum crystallization temperature $\left(T_{\mathrm{c}, \mathrm{m}}\right)$ for both TPVs shifted to a higher temperature. This higher crystallization temperature is attributed to the presence of the dispersed EPDM particles, which act as heterogeneous nuclei that started the crystallization at higher temperatures. In the 30/70 TPV, there was no significant change in melt enthalpy $\left(\Delta \mathrm{H}_{\mathrm{m}}\right)$, whereas the melt enthalpy increased in the case of the 50/50 TPV. This melt enthalpy behavior is attributed to the formation of in situ PP-EPDM graft-links in the 50/50 TPV because of the increased amount of heat required to melt PP during the scan that led to the higher melt enthalpy. The formation of in situ graft-links was also confirmed from the $>100 \%$ gel content for the 50/50 TPV.

Figure 16 shows the variation of the apparent shear viscosity and shear stress with the apparent shear rate for the two TPVs prepared. In Figure 16, all of the control and TPV samples followed shear-thinning behavior, that is, they acted like pseudoplastic materials. It was noted that that shear viscosity decreased with increasing apparent shear rate. For the 30/70 TPV, the decrease in the shear viscosity was similar to the control sample in spite of the cross-linked EPDM phase in the TPV. However, the 50/50 TPV exhibited a significant reduction in the shear viscosity relative to the control sample, especially between $100-1000 \mathrm{~s}^{-1}$ shear rates, which falls in the range of most of the extrusion operations. Similar behavior was observed in the flow curve of shear stress at different shear rates, which was found to follow a power law, that is, shear stress increased with increasing apparent shear rate. Although the 30/70 TPV followed the same flow curve as that of the control sample, the 50/50 TPV showed decreased shear stress compared with the control sample, especially between $100-1000 \mathrm{~s}^{-1}$ shear rates. Thus, it can be concluded that the 50/50 TPV demonstrated better processing behavior than the 30/70 TPV, and the processing was much better compared with the control sample itself. This improved behavior for the 50/50 TPV is attributed to the increased viscosity of EPDM because of cross-linking via EIReP; the viscosity of PP; however, decreased because of the thermal load as well as to controlled degradation during EIReP. Thus, the increase in the viscosity of EPDM and the decrease in the viscosity of PP complement each other during the processing of the 50/50 TPV.

\section{CONCLUSIONS}

PP-EPDM TPVs were prepared via EIReP without any cross-linking agents. The effect of different absorbed doses and different dose per rotation values on the morphology and properties of the TPVs was studied. The absorbed dose controls the amount of cross-linking of the EPDM, whereas the dose per rotation is expected to have an influence on the morphology development of the TPVs during EIReP. The premixing time before the dynamic vulcanization has not previously been studied in detail in the literature. It was expected 

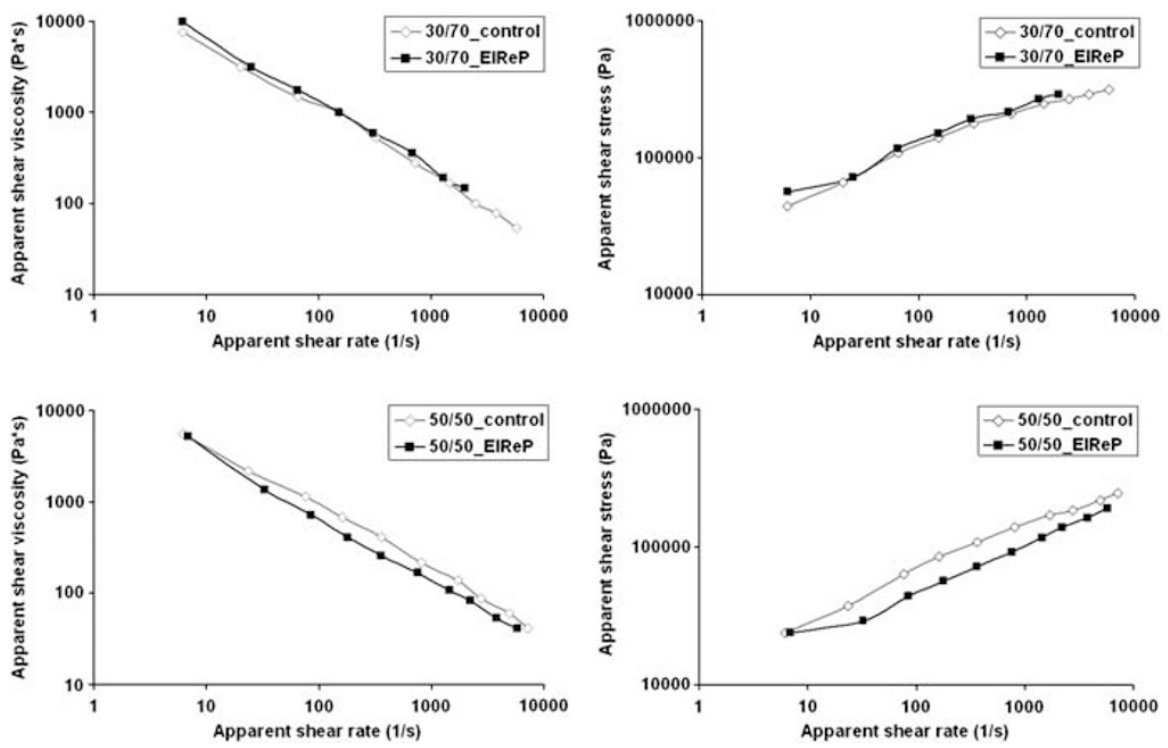

Figure 16 The variation of the apparent shear viscosity and the shear stress with the apparent shear rate for the two TPVs prepared, along with their control samples.

that the premixing time before EIReP would have a prominent effect on morphology development, and hence on the mechanical properties during EIReP. Before EIReP, the morphology developed during melt mixing of PP-EPDM and the dispersion of EPDM in PP strongly influences the final morphology and properties of the TPVs. Thus, different premixing times before EIReP were studied. The blend ratio of the PP and EPDM is very crucial in determining the properties of the TPVs. The blend ratio also affects the viscosity ratio of the blend components, which in turn influences the morphology and hence the properties of the TPVs prepared. Thus, the effect of different blend ratios on the morphology and properties of the TPVs was also studied. On the basis of the results obtained from the above mentioned studies, the following conclusions were made:

(a) The absorbed dose and the dose per rotation both exhibited significant influence on the morphology and the properties of the TPVs. TPVs produced with a dose of $100 \mathrm{kGy}$ and a dose per rotation of $90 \mathrm{kGy}$ per rotation exhibited the best mechanical properties of all the TPVs prepared. The SEM images showed that there was a broad distribution of the EPDM particle size in the TPVs prepared. The particle size varied from $1 \mu$ to a few hundreds of nanometers. TPVs with this type of inhomogeneous morphology exhibited the best set of mechanical properties.

(b) There was a prominent effect of premixing time before EIReP on the final morphology and properties of the TPVs prepared. TPVs with the best set of mechanical properties were obtained when the premixing time was $14 \mathrm{~min}$. From the SEM images, after a premixing time of $14 \mathrm{~min}$, the EPDM was homogeneously dispersed in PP and the phase inversion already took place. Thus, during EIReP, EPDM was further dispersed into smaller particles because of high shearing forces. This resulted in superior mechanical properties of the TPVs with premixing time of $14 \mathrm{~min}$.

(c) The blend ratio had an important role in the morphological development and final properties of the TPVs prepared. It was found that at a 30/70 PP/EPDM blend ratio, EPDM and PP formed co-continuous phase morphology, and hence the properties were not significantly improved. However, at a 50/ 50 blend ratio, EPDM was dispersed in the continuous PP phase, and therefore the resulting TVP had excellent mechanical properties. At higher EPDM concentrations, the viscosity ratio was too high, which resulted in incomplete phase inversion, and hence average mechanical properties of the TPVs prepared.

1 Pakula, T., Saijo, K., Kawai, H. \& Hashimoto, T. Deformation behaviour of styrenebutadiene-styrene triblock copolymer with cylindrical morphology. Macromolecules 18 , 1294-1299 (1985).

2 Séguéla, R. \& Prud'homme, J. Affinity of grain deformation in mesomorphic block copolymers submitted to simple elongation. Macromolecules 21, 635-641 (1988).

3 Polizzi, S., Bösecke, P., Stribeck, N., Zachmann, H. G., Zietz, R. \& Bordeianu, R. Small angle $\mathrm{X}$-ray scattering investigations of styrene-butadiene-styrene block copolymers during stretching. Polymer 31, 638-644 (1990).

4 Fujimura, M., Hashimoto, T. \& Kawai, H. Structural change accompanied by plasticto-rubber transition of SBS block copolymers. Rubb. Chem. Technol. 51, 215-219 (1978).

5 Hashimoto, T., Fujimura, M., Saijo, K., Kawai, H., Diamant, J. \& Shen, M. Strain induced plastic to rubber transition of a SBS block copolymer and its blend with PS. Adv. Chem. Ser. 176, 257-263 (1979).

6 De, S. K. \& Bhowmick, A. K. Thermoplastic Elastomers from Rubber-Plastic Blends (Ellis Horwood, Chichester, UK, 1990).

7 Coran, A. Y. \& Patel, R. P. Thermoplastic elastomers based on dynamically vulcanized elastomer/thermoplastic blends. in Thermoplastic Elastomers, 2nd edn (eds Holden, N. R. et al) (Hanser Publishers, Munich, Germany, 1996).

8 Karger-Kocsis, J. Thermoplastic rubbers via dynamic vulcanization in Polymer Blends and Alloys (eds Shonaike, G. O., Simon, G. P.) (Marcel Dekker, New York, USA, 1999).

9 Gessler, A. M. \& Haslett, W. H. (to Esso Research and Engineering Co.). U.S. Patent 3,037,954, June 5, 1962.

10 Fisher, W. K. (to Uniroyal Inc.). U.S. Patent 3,758,643 September 11, 1973.

11 Coran, A. Y., Das, B. \& Patel, R. P. (to Monsanto Co.). U.S. Patent 3,130,535, December 19, 1978.

12 Coran, A. Y. \& Patel, R. P. Rubber thermoplastic compositions Part I. EPDM polypropylene thermoplastic vulcanizates. Rubb. Chem. Technol. 53, 141-150 (1980).

13 Speri, W. M. \& Patrick, G. R. Fiber reinforced rubber modified polypropylene. Polym. Eng. Sci. 15, 668-672 (1975).

14 Van der Wal, A. Ph.D. Thesis (University of Twente, Enschede, The Netherlands, 1996).

15 Duin, M.van \& Machado, A. V. EPDM based thermoplastic vulcanisates: crosslinking chemistry and dynamic vulcanisation along extruder axis. Polym. Degrad. Stab. 90, 340-345 (2005).

16 Duin, M.van Recent developments for EPDM based thermoplastic vulcanisates. Macromol. Symp. 233, 11-16 (2006). 
17 Datta, S., Naskar, K., Jelenic, J. \& Noordermeer, J. W. M. Dynamic vulcanized thermoplastic vulcanizates by multifunctional peroxides: characterization with various analytical techniques. J. Appl. Polym. Sci. 98, 1393-1403 (2005).

18 Naskar, K. \& Noordermeer, J. W. M. Influence of various peroxides on PP-EPDM thermoplastic vulcanizates at different blend ratios. J. Elast. Plast. 38, 163-180 (2006).

19 Naskar, K., Gohs, U., Wagenknecht, U. \& Heinrich, G. Development of PP-EPDM thermoplastic vulcanizates by electron induced reactive processing. eXPRESS Polym. Lett. 3, 677-683 (2009).

20 Goharpey, F., Katbab, A. A. \& NAzockdast, H. Mechanism of morphology development in dynamically cured EPDM/PP TPEs I. Effect of state of cure. J. Appl. Polym. Sci. 81, 2531-2544 (2001).
21 Avgeropoulos, G. N., Weissert, F. C., Biddison, P. H. \& Böhm, G. G. A. Heterogeneous blends of polymers - rheology and morphology. Rubber Chem. Technol. 49, 93-104 (1976).

22 Jordhamo, G. M., Manson, J. A. \& Sperling, L. H. Phase continuity and inversion in polymer blends and simulataneous interpenetrating networks. Polym. Eng. Sci. 26, 517-524 (1986).

23 Utracki, L. A. On the viscosity-concentartion dependence of immiscible polymer blends. J. Rheol. 35, 1615-1637 (1991).

24 Stocker, W., Magonov, S. N., Cantow, H.- J., Wittmann, J. C. \& Lotz, B. Contact faces of epitaxially crystallized alpha and gamma phase isotactic polypropylene observed by atomic force microscopy. Macromolecules 26, 5915-5923 (1993).

25 I' Abee, R. PhD Thesis (TU Eindhoven, The Netherlands, 2009).

26 Thakur, V. Master Thesis (IIT Kharagpur, India, 2008). 